Content list available at ICONSMAT

Journal of Construction Materials

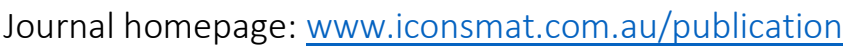

Article history:

Received 30 July 2021

Received in revised form

7 August 2021

Accepted 7 August 2021

Available online 7 August 2021

\title{
Effective Leadership in the Engineering, Technology, and Construction Industry
}

\author{
David W. Farler ${ }^{1 *}$, Perry Haan ${ }^{1}$ \\ ${ }^{1}$ Tiffin University, Tiffin, OH, 44883, USA \\ *Corresponding author: E: farlerd@tiffin.edu
}

\begin{abstract}
This paper explores what effective leadership is being employed in the engineering, technology, and construction (ETC) industry. Organizations need to understand what character traits are being used and what leadership styles work to promote sustainability and improve the triple bottom line. This paper looks at multiple publications on leadership and character traits effective for managers and leaders in the ETC industry. The ETC industry is a trillion-dollar industry, and understanding ways to improve leadership is vital for organizations' successful outcomes. With improvements to the managerial and leadership, there could be ways for organizations to profit more and cut down on cost costs. Finding ways to improve motivation can help organizations improve safety, improve culture, and increase employee motivation. From the research, this paper has found that situational leadership, transformational, and transactional are the most effective leadership styles that individuals can use in the ETC industry for leadership. Character traits that are the most effective have been identified in this research paper. This research has contributed to the ways individuals who start in the engineering and technology industry can improve upon their leadership skills as they are promoted into managerial and leadership roles. The need for managerial positions in the ETC industry, such as project and construction managers, to improve is vital for successful outcomes and creating a high-level performance. The study helps provide a gap in the limited research available to improve ETC leadership for all organizations' present and future.
\end{abstract}

DOI: 10.36756/JCM.v2.4.8 (C2021 Institute of Construction Materials

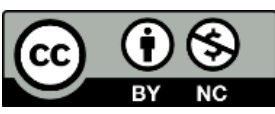

\section{Keywords}

Construction, effective leadership, engineering, technology. 


\section{Introduction}

Leadership is an essential behavior, asset, and attribution for managers in the ETC industries. Understanding what characteristic traits are being employed in the recent decades and today is essential for leaders and managers. Bonasso discussed how engineers need to advance in leadership capabilities and become more involved in leadership by "adopting and advancing an integral philosophy" [4, p.17]. There is an agreement among scholars and practitioners that leadership is vital for successful outcomes for organizations and essential for creating high-level performance [1]. This paper will use the definition of leadership defined by Northouse "as a process whereby an individual influences a group of individuals to achieve a common goal" [19, p.5].

The United States has an average near \$1 trillion yearly worth of construction spending since 2003 [20]. With so much money being spent in the engineering and construction industry annually in the United States, focusing on appropriate leadership techniques for managers leading engineering and construction execution is essential. Understanding ways to improve and train leaders to be more effective is vital for a trillion-dollar industry in the United States. Proper leadership by managers and individuals in the engineering and construction sectors would positively return cost savings from better designs, productivity, safety, and sustainability in the workforce. There is also the possibility of enhancing employees' capabilities, morals, motivation, retention, and development to improve the organization they work at or for. Giegold discussed how engineering management areas could improve leadership areas and focus on motivation, communication, team-building, discussion of performance, resolving conflicts, disciplining, and dealing with individuals' emotional side [11].

It is vital for technical professionals who start in the engineering or technology sectors and advance into management roles to having beneficial leadership traits. These roles turn into being the managers of engineer personnel, construction personnel, projects, and other leadership sectors. This limited experience of only performing technical tasks can create an issue of not understanding what it takes to be an effective manager and leader among peers. Asree et al. stated: "project managers need to gain insights about the various leadership styles, traits, and behaviors they exhibit in an organizational setting" [1, p.360]. "Effective leaders prove extensive life experience and the ability to focus their teams' interests away from conflict and towards results, providing progress opportunities as well as constructive approaches" [5, p.111].

Individuals in the engineering and construction sector who transition from a technical role into a managerial role must understand how to lead effectively. This paper will use the definition of effective engineer leadership defined by Newport: "to be influential leaders, engineers must possess written, oral communication, customer relations, personal initiative, teamwork abilities, organizational knowledge, and decision-making to facilitate the development of solutions to business challenges" [18, as cited in [6], p.10]. Leadership is a crucial component for organizations' success across the United States to promote sustainability and the triple bottom line. Organizations in the engineering and construction industry can improve upon their capabilities by focusing on leaders of today and the future. According to Mendenhall et al., global leadership is "the processes and actions through which an individual influence a range of internal and external constituents from multiple national cultures and jurisdictions in a context characterized by significant levels of task and relationship complexity" [17, p.23]. Identifying what management leadership traits are employed by managers in the ETC industry will be discussed in this paper. This paper will focus on what leadership types are effective in the ETC industry and what characteristic leadership traits are preferred by employees. 


\section{Employees in engineering and technology}

The leadership traits employees are looking for in a leader from management in the ETC industries are vital for organizations to recognize. The construction industry just in the United States has an approximate average of $\$ 1$ trillion spent every year since 2003 [20]. With such an extensive industry leadership is vital for the improvements of employees working in this sector. This improvement could help reduce costs on projects, improve the design, improve safety, improve cultures, and make construction and engineering projects more successful.

Engineering and technology professionals do more than just design work for the construction industry; there is also all the work for manufacturing, medical, energy, and other industries. Products such as computers, medical devices, software, automotive, and other products and services are an enormous industry full of engineers or technology professionals. Arvey and Neel looked at their managers' engineering style and found out that leader consideration and employee expectancies do have a parallel relationship for job performance [2]. Job performance was more significant when an intrinsic motivation took place by engineers when management creates tasks that can provide a sense of accomplishment and achievements. The parallel connection between managers being great leaders and employees' performance is vital for organizations to recognize.

\section{Managers and leadership}

Managers in the ETC industries play a vital role in improving sustainability and the triple bottom line. Professionals such as engineers rely on their managers to help guide them in their careers. Part of a manager's job is to motivate employees, develop and improve their subordinates' overall capabilities. Engineers or technical professionals can become project managers, managers of engineers, or management of construction. Many industry managers were engineers who performed a technical role and are then supposed to transition into employee roles. Laasch and Conaway discussed how sustainability is being able to maintain three different types of capital that include economic, environmental, and social [16]. Management plays a vital role for any organization to help promote sustainability and improve the triple bottom line.

Leaders and managers in an organization must know the values they are trying to achieve and what structure to have for their organization. Leaders of the ETC industry play a vital role in the performance of their employees. Intrinsic motivation is from the inside, and the internal desire of an individual was extrinsic is external like a reward or bonus [8]. Dawson and Andriopoulos discussed that organizations exist in a changing environment, and to survive, they must develop abilities to adapt. Understanding an organization's culture as a leader is part of having the proper traits and characteristics to lead successfully [8]. Suppose this does not happen; how are workers supposed to know what quality of a product is, how to increase throughput, how to look out for each other, and help the overall success and profit margin of the business. Glass discussed that leaders are more important to today's society in the engineering and technology industry because of the rapid pace of changes [12]. With changes occurring and the need for engineers to become leaders, Glass discussed how universities are now trying to influence some training in curriculum towards leadership skills such as communication, ethics, and management and not just technical [12]. Table I introduces articles that were looked at in this paper to show what the ETC industry utilizes for the most effective leadership type and characteristic traits employees look for in a leader. 
Table 1 - Research compilation of leadership styles and character traits for success

\section{Researcher \\ Effective leadership type concluded Effective characteristic traits}

Veliu et al. [21]

Transformational, Democratic,

Autocratic

Zulkiffli and Latiffi [24]

Communication and teamwork are most effective. Other traits should be used: motivation, decision-making, conflict management, delegation, planning, team-building, negotiation

Giegold [11]

Technical, motivating, influencing, achieving missions, goals, \& values, communication, team-building, resolving conflict, discussion of performance

Cismas et al. [5]

Providing feedback, communication, persuading others, take action or risk

Farr et al. [9]

Big thinker in quality and responsibility, ethical and courageous, masters change, risktaker, a mission that matters, uses power wisely, a team builder, and a good communicator

\begin{tabular}{lll}
\hline Cunningham et al. [7] & $\begin{array}{l}\text { Coaching Leadership and Strategic } \\
\text { Leadership }\end{array}$ \\
\hline Henkel et al. [13] & Situational Leadership & $\begin{array}{l}\text { Motivation, inspiring, interpersonal } \\
\text { skills, and communication are just as } \\
\text { important as technical skills }\end{array}$ \\
\hline
\end{tabular}

Kelly and MacDonald Democratic

[15]

\begin{tabular}{ll}
\hline Ismail and Fathi [14] & Situational Leadership \\
\hline Asree et al. [1] & Transformational and Transactional \\
\hline Wipulanusat et al. [22] & $\begin{array}{l}\text { Transformational and Consideration } \\
\text { Leadership }\end{array}$ \\
\hline Zulch [23] & Situational Leadership
\end{tabular}

Newport [18]

Written, oral communication, customer relations, personal initiative, teamwork abilities, organizational knowledge, and decision-making

\section{A. Effective Leadership Styles}

"Leadership plays a vital role in building the process, structures, and climate for an organization to become innovative and to motivate team expectations toward innovations" [22, p.7]. Zulch stated for 
project management: "An effective leader will be able to adapt a style or combination of styles to suit the circumstances" [23, p.173]. Understanding what leadership style works for employees is vital for the success and the effectiveness of management for an organization.

According to Bannerman project success is "measure of the immediate performance of a project against its main design parameters-schedule (time), budget (cost), scope, and quality-which the literature tends to call a measure of project management success" [3, p.3]. Gaddis defined a project as "a project is an organization unit dedicated to the attainment of a goal - generally the successful completion of a developmental product on time, within budget, and in conformance with predetermined performance specifications" [10, p.89]. A project's success relies heavily on how a project manager or construction manager leads the group that is a part of the team.

In project management, Asree et al. discussed how project leaders play an essential role in motivating the team, meeting project objectives, reducing cost and time constraints, and using a specific leadership style depending on the project's nature [1]. There are different types of managers in the ETC industry. Ismail and Fathi discussed how project managers need to use all different leadership styles [14]. Per Ismail and Fathi, the leadership styles that a project manager must utilize depending on the phase of a project are transformational, transactional, full-range leadership, servant, contextual, safety specific transformational, and charismatic leadership [14].

Asree et al. discovered that transformational and transactional leadership are both needs for a project manager's success, depending on the project phase [1]. Wipulanusat et al. found that transformational and consideration leadership are vital for managers' success to motivate engineering professionals [22]. With both leadership styles, characteristic traits such as motivating individuals, encouraging innovation, development of subordinates, cultivating relationships, open to new ideas, achieving results, accepting diversity, committing to safety, and treating individuals with respect are the most vital traits to process $[22$, p.14].

Even with a shift of leadership styles because the styles can change from project to project, or group to group, the communication between the individuals working for a project manager remains an intrinsic part of leadership [23]. Overall, a project manager must adapt to different leadership styles depending on the group or project and utilize effective communication. The trait of communication is not limited to language only, but also includes personality, behavior, attitude, and nonverbal such as body language. Overall, it can be defended that a project manager in a leadership role for engineers, technicians, and construction employees must use situational leadership style for success [23].

Veliu et al. discussed that leadership styles do have to adapt depending on the situation and individuals being led [21]. Still, leadership does have a parallel relationship with employee performance. The ETC sector is different from that of other industries and would require a different leadership style for managers to lead effectively. Veliu also discovered in their quantitative research that the three leadership styles of transformation, democratic, and autocratic have the most positive impact on employee performance [21].

Cunningham et al. looked at project managers and the six leadership styles of coaching, strategic, lassiez-faire, bureaucratic, autocratic, and democratic [7]. The research concluded that the project management industry had little to no effect and that all individuals involved with project management prefer coaching leadership and strategic leadership the most. However, the industries were also limited to healthcare, pharmaceutical, and financial. There could be a delta in research if other manufacturing, chemical, energy, and others were included.

Henkel et al. looked at project manager leadership behavior through quantitative analysis that showed a more valuable situational leadership style approach than a one-type leadership style [13]. Project 
managers manage projects with constraints on scope, time, costs, and safety while utilizing a broad field of individuals from the technical and construction industry. The adaptation to using different leadership styles with the appropriate characteristic traits can influence the project's success. Henkel et al. discussed that qualities such as motivation, inspiration, interpersonal skills, and communication are just as critical as project managers' technical skills [13]. These qualities are vital for engineers to understand when taking on these roles; other skills and assets besides technical matter in management success.

Kelly and MacDonald researched effective leadership; the types of leadership which involve communication types looked at in their study were authoritarian, democratic, laissez-faire, and bureaucratic [15]. After Kelly and MacDonald interviewed 340 participants, the majority wanted democratic leadership. According to Kelly and MacDonald democratic leadership, "encourages subordinate input in decisions and engages in two-way communication with his/her subordinates" [15, p.435].

\section{B. Leadership Character Traits that Employees Prefer}

Leadership characteristic traits are vital to the ETC industries. Understanding what traits employees are yearning for from their managers can help with employee performance. This understanding and knowledge can also help managers drive toward being a better leader and shift to the leadership style that will be most effective with their team [18].

Zulkiffli and Latiffi found that communication and teamwork are essential skills for project managers in sustainable construction projects [24]. However, it still takes other skill sets and traits for project managers to be successful, according to Zulkiffli and Latiffi [24]. Besides communication and teamwork, other skills or characteristic characteristics useful for project managers are motivation, decisionmaking, conflict management, delegation, planning, team-building, and negotiation.

Giegold looked at engineering management's essentials and three distinct critical skills: technical, conceptual, and human skills [11]. The technical portion is still significant, being an engineering and technical manager. Still, other factors such as conceptual skills and that deal with items such as influencing, motivating, achieving missions, goals, and values are just as essential, and so is human skills that deal with motivating, communication, team-building, resolving conflict, and discussing performance [11].

Cismas et al. concluded that an effective leader must understand how to adapt and assess personal strengths with shortcomings [5]. Great influential leaders should understand how their team fits into the big picture to achieve a successful outcome of its goals, strategies, and targets. The four traits vital for a leader from their research are listening and providing feedback, communication, persuading ideas to make followers believe in them, and convincing others to take action, for it is ok to take a risk and make mistakes.

Farr et al. discussed that engineers must develop into leadership roles faster than their predecessors with fast changes with modern engineering [9]. Farr et al. went on to discuss senior engineers have been successful because they demonstrated technical excellence but must develop into a leader [9]. This development can be done by continuing to work on nine characteristic traits. The nine traits are being a big thinker in quality and responsibility, ethical and courageous, masters change, risk-taker, a mission that matters, use power wisely, a team builder, and a good communicator [9]. 


\section{Conclusion}

This research study provided information on leadership types in the engineering and technology sector and what traits are effective in leadership. Some managerial roles, such as project management in the engineering and construction industry, require a diverse understanding of different leadership styles throughout the phase of a project. This information could also be determined as using situational leadership for a project manager. Other roles, such as engineers' manager, look for managers to lean toward transformational and consideration leadership. To help create a high performance like Asree et al. discussed in the ETC industry is vital [1]. Excellent leadership and understanding what type of leadership is effective with the effective characteristic traits can help improve motivation, communication, team-building, and performance [11].

The types of leadership used by managers in the ETC sector and what traits are effective in leadership have been summarized from the research. The study's reoccurring characteristics that are effective for managers and leaders in the ECT industry have been identified from this paper's analysis. The research also provides insight that some specific traits are effective in helping to motivate individuals in what they look for in a leader.

References [5], [9], [11], [13], [18], [24] showed traits that leaders should possess. The characteristics are communication, attitude, behavior, motivating individuals, encouraging, innovation, development of subordinates, cultivating relationships, being open to new ideas, achieving results, accepting diversity, committing to safety, and treating individuals with respect are the most vital traits process. From [1], [7], [13]-[15], [21]-[23], there is a connection that effective leadership types such as transformation, situational, and transactional can be effective to help the improvement of the sustainability, motivation, and productivity at organizations.

There is a lack of research for management and leadership in the ETC industries. More research should be conducted on what employees are looking for in their leaders as engineers, technical individuals, or construction industry professionals. Having quantitative analysis to investigate what traits are preferred by employees in leadership by managers in the engineering and technology sector is vital to a trilliondollar industry. Bettering leadership in this concentrated industry can help strive for improvements for employees' motivation, sustainability for all, and the triple bottom line of an organization. Investigating the situational leadership style more on the key traits employees in the ETC sector value in a leader and manager needs to be researched more through quantitative research. This research continuation can provide added value for improving leadership and management throughout the ETC sector, which will enhance sustainability and the triple bottom line for an organization.

This paper has some limitations. The study was also limited with a lack of quantitative research in the management and leadership field of ETC sectors. The literature provides insights into how there is a relationship between leadership styles and character traits that can improve managers' leadership capabilities. References [5], [9], [11], [13], [18], [24] found that traits such as motivating employees and effective communication are significant for leaders. References [13], [14], and [23] found that there is a connection between great leaders and situational leadership. There is limited research for defined areas in the globe and the United States. With different cultures and laws, types of leadership and traits could be different. This paper's gathering of information provides a need for further research into what employees in the ETC industries are looking for in a manager and leader. The major limitation is that this is a nonempirical paper and empirical work needs to be done.

\section{Acknowledgment}

David W. Farler and Perry Haan thank Tiffin University Ph.D. faculty and staff. David W. Farler also thanks Dr. Perry Haan for the support in this research and mentorship throughout the Ph.D. program. 


\section{References}

[1] Asree, S., Cherikh, M., \& Baucum, C. (2019). A review of leadership styles that affect project success. International Journal of the Academic Business World, 13(1), 36-46.

[2] Arvey, R. D., \& Neel, C. W. (1974). Moderating effects of employee expectancies on the relationship between leadership consideration and job performance of engineers. Journal of Vocational Behavior, 4(2), 213-222.

[3] Bannerman, P. L. (2008). Defining project success: a multilevel framework. In Proceedings of the Project Management Institute Research Conference (pp. 1-14).

[4] Bonasso, S. G. (2001). Engineering, leadership, and integral Philosophy. Journal of Professional Issues in Engineering Education \& Practice, 127(1), 17. https://doi.org/10.1061/(ASCE)10523928(2001)127:1 (17)

[5] Cismas, S. C., Dona, I., \& Andreiasu, G. I. (2016). Responsible leadership. Procedia - Social and Behavioral Sciences, 221, 111-118. doi: 10.1016/J.SBSPRO.2016.05.096

[6] Crumpton-Young, L., McCauley-Bush, P., Rabelo, L., Meza, K., Ferreras, A., Rodriguez, B., Millan, A., Miranda, D., \& Kelarestani, M. (2010). Engineering leadership development programs a look at what is needed and what is being done. Journal of STEM Education: Innovations \& Research, 11(3/4), 10-21.

[7] Cunningham, J., Salomone, J., \& Wielgus, N. (2015). Project management leadership style: A team member perspective. International Journal of Global Business, 8(2), 27-54.

[8] Dawson, P., \& Andriopoulos, C. (2017). Managing change, creativity \& innovation. Sage

[9] Farr, J. V., Walesh, S. G., \& Forsythe, G. B. (1997). Leadership development for engineering managers. Journal of Management in Engineering, 13(4), 38-41.

[10] Gaddis, P. O. (1959). The project manager. Harvard Business Review, 37(3), 89-97.

[11] Giegold, W. (1981). Leadership - The essential of engineering management. Engineering Management International, 1(1), 49-56. doi:10.1016/0167-5419(81)90008-9

[12] Glass, J. T. (2006). Leadership and teamwork in engineering. Leader to Leader, 2006(S1), 24-26. doi:10.1002/LTL.349

[13] Henkel, T., Marion, J., \& Bourdeau, D. (2019). Project manager leadership behavior: Taskoriented versus relationship-oriented. Journal of Leadership Education, 18(2), 1-14.

[14] Ismail, M., \& Fathi, M. S. (2018). Leadership in construction: leadership styles practiced in construction project-a review. Journal of Advanced Research in Business and Management Studies, 13(1), 24-30.

[15] Kelly, S., \& MacDonald, P. (2019). A look at leadership styles and workplace solidarity communication. International Journal of Business Communication, 56(3),432-448. https://doi.org/10.1177/2329488416664176 
[16] Laasch, O. \& Conaway, R., N. (2015). Principles of responsible management: Global sustainability, responsibility, and ethics. Stamford, USA: Cengage Learning.

[17] Mendenhall, M.E., Osland, J.S., Bird, A., Oddou, G.R., Stevens, M.J., Maznevski, M., \& Stahl, G. (2018). Global leadership: Research, practice and development. New York, NY: Routledge.

[18] Newport, C. L., \& Elms, D. G. (1997). Effective engineers. International Journal of Engineering Education, 13(5), 325-332.

[19] Northouse, P. G. (2019). Leadership: Theory and practice. (8th ed.). Los Angeles, CA: Sage ePublishing.

[20] United States Census Bureau. (2021).

https://www.census.gov/construction/c30/prpdf.htm|

[21] Veliu, L., Manxhari, M., Demiri, V., \& Jahaj, L. (2017). The influence of leadership styles on employee's performance. Management (16487974), 31(2), 59-69.

[22] Wipulanusat, W., Panuwatwanich, K., \& Stewart, R. A. (2017). Exploring leadership styles for innovation: an exploratory factor analysis. Engineering Management in Production and Services, 9(1), 7- 17.

[23] Zulch, B. (2014). Leadership communication in project management. Procedia-Social and Behavioral Sciences, 119, 172-181.

[24] Zulkiffli, N. A., \& Latiffi, A. A. (2019). Review on project manager's leadership skills in the preConstruction phase of sustainable construction projects. In MATEC Web of Conferences (Vol. 266, p. 01011). EDP Sciences.

[25] T. Boulos, F. Sartipi, and K. Khoshaba, "Bibliometric analysis on the status quo of robotics in construction," Journal of Construction Materials, vol. 1, pp. 2-3, 2020.

[26] F. Sartipi, "Diffusion of Innovation Theory in the Realm of Environmental Construction," Journal of Construction Materials, vol. 1, pp. 4-2, 2020, doi: https://doi.org/10.36756/JCM.v1.3.2.

[27] F. Sartipi, "Dynamic data processing for building energy consumption," Journal of Construction Materials, vol. 2, no. 2021, pp. 2-4, 2020, doi: https://doi.org/10.36756/JCM.v2.2.4.

[28] V. Tam, F. Sartipi, and K. N. Le, "Gaps between supply and demand of recycled aggregate: Sydney metropolitan case study," Presented at the CRIOCM 2018, 2018.

[29] F. Sartipi, "Influence of $5 \mathrm{G}$ and IoT in construction and demolition waste recycling-conceptual smart city design," Journal of Construction Materials, vol. 1, pp. 4-1, 2020, doi: https://doi.org/10.36756/JCM.v1.4.1.

[30] F. Sartipi, "Negative interest rate: Way to tackle inflationary housing prices," Journal of Construction Materials, vol. 2, pp. 4-1, 2021, doi: https://doi.org/10.36756/JCM.v2.4.1.

[31] F. Sartipi, "Organizational structure of construction entities based on the cooperative game theory," Journal of Construction Materials, vol. 1, no. 2, 2020, doi: https://doi.org/10.36756/JCM.v1.3.3 
[32] J. Luliano, A. Singh, and F. Sartipi, "Political-economical evaluation of CO2 capture in Australian building sector," Journal of Construction Materials, vol. 1, pp. 3-2, 2020, doi: https://doi.org/10.36756/JCM.v1.3.2.

[33] F. Sartipi, "Publicizing construction firms by cryptocurrency," Journal of Construction Materials, vol. 2, pp. 3-1, 2021, doi: https://doi.org/10.36756/JCM.v2.3.1.

David W. Farler Columbus Grove, Ohio born March 15, 1984. Bachelor of science in mechanical engineering, Ohio Northern University, Ada, Ohio, United States, 2008, master of business administration in general management, Tiffin University, Tiffin, Ohio, United States, 2013, doctor of philosophy in global leadership and change Tiffin University, Tiffin, Ohio, United States, current.

He is currently a Senior Major Project Manager and Turnaround Lead at bp for the United States. Previously he was a Senior Project Engineer, Maintenance Engineer, Design Engineer, Process Operator, and Pipefitter throughout his professional career. He has over a decade of experience in the oil, gas, chemical, and energy industry in multiple roles.

Perry Haan Bachelor of science in business administration, The Ohio State University, Columbus, Ohio, United States, master of business administration in general management, Xavier University, Cincinnati, Ohio, United States, doctor of business administration, University of Sarasota, Sarasota, Florida, United States.

He is currently a Professor of Marketing \& Entrepreneurship and a Ph.D. Academic Advisor at Tiffin University. Previously he has taught in eight countries outside of the United States.

Dr. Perry Haan has won teaching awards at three difference institutions or higher learning, won the 2016-2017 Tiffin University Scholarship Award, 2017 Fulbright Scholarship to teach Nepal, and 2010 awarded a Fellowship by the International American Association of Financial Management. He has authored or co-authored over 90 peer reviewed articles and co-authored a text book, Practical Statistics for Business. 